\title{
APPLICATION OF MANAGEMENT TABULATION CHIEFLY BASED OBLIGATION INQUIRY IN METHOD CORPORATION
}

\author{
DR.PV SHARMA \\ DEPT. OF MECHANICAL ENGINEERING ACN COLLEGE OF ENGINEERING ALIGARH, UTTAR \\ PRADESH
}

\begin{abstract}
In any case failures can't be eliminated. However, a stronger understanding of the causes and mechanisms of apparatus failure will permit failure management measures to be developed and enforced. irresponsibleness is the pricey half of the economic equation and adopting measures to improve liableness and availableness of the system can ultimately result in economic gain. The gift work tries to arrive at a benchmark price in terms of part failure rate and liableness and there by reach the internet impact of modification that is needed for a system up-gradation. The tactic involves plotting management tabulations for individual parts mistreatment the time to fail. The central line of the management tabulation corresponds to the Mean Time Between Failure (MTBF) and area unit placed at a distance of $\sigma 3 \pm$ from the mean line and relies on $\mathrm{t}$ - distribution. The parts requiring Associate in nursing improvement in respect of failure rate is known by analyzing the management tabulations. the specified amendment in the part availableness as well as the system availableness will be obtained Associate in Nursing an estimate of net impact of modification is conjointly arrived. The model will offer a live of the performance of the parts similarly as that of the system. The quantification of the enhancements needed, if any, is obtained mistreatment the model. An eleven step rule is conjointly developed primarily based on the model. It is hoped that the developed model and rule can sway be a robust tool in method reliableness analysis.
\end{abstract}

Key words: availableness, management tabulation, Failure rate, Mean Time between Failure (MTBF), method reliableness. 


\section{INTRODUCTION}

Irresponsibleness of any part or system is its chance of success. Irresponsibleness and handiness place a very important role choose the economic practicableness of any system [Shouri and Sreejith, 2008]. A method system generally are going to be created of a variety of parts and the system irresponsibleness can rely upon the system configuration as well as the individual part irresponsibleness. That is, however sensible system is can rely upon however sensible the individual parts ar. thus it is very important that every and each part or forms up to its most capable limit while not failure. No business will progress effectively while not the information of implementation of irresponsibleness engineering. These days it's developed to a high degree of refinement and quantification. irresponsibleness engineering provides the theoretical and sensible tools whereby the chance and capability of elements, components, equipment, products, sub-systems and systems to perform their needed functions while not failure for desired periods of nominative environments. irresponsibleness and risk analyses have historically been conducted in order to give data for stakeholders as basis for, or aid in, decision-making.

One of the call creating tools used in total quality management (TQM) is applied mathematics method management (SPC). once applied with success to producing processes, SPC improves product quality and productivity, reduces production prices and will increase profits. In its simplest kind SPC is applied on to a method variable obtained from a method that is to be management led. The method variable is aforethought on applied mathematics management tabulation (cc). The $\mathrm{cc}$ is comprised of the mean of the method variable, associate higher management limit (UCL) and a lower management limit (LCL). If observations on the method variable fall higher than the $U C L$ or below the $L C L$, the method is taken into account to be out of management. This condition is considered being because of a special cause touching the method mean. Duncan[1956] introduced the style of management tabulation on the basis of economic criteria. 


\section{The American Journal of \\ Engineering and Technology}

\section{VOLUME01 ISSUE01}

This section describes the development of a model for benchmark reliableness assessment of system parts victimization management tabulation technique. associate degree formula is conjointly developed to create associate degree assessment of the value edges, in case the part MTBF and reliableness falls below the benchmark worth and wants improvement. The model relies on the subsequent assumptions:

1)Process parts square measure assumed to have a constant failure rate as well as a relentless repair rate.

2) Handiness into account is steady state handiness.

3) Interest rate is constant throughout.

4) Depreciation of the plant isn't thought-about.

\section{ALGORITHM FOR INBOUND AT THE WEB RESULT OF MODIFICATION}

Step algorithmic rule has been developed for inbound at the benchmark irresponsibleness values of the system elements and inbound at the web result of modification that's needed for the system. The overall value of modification is obtained by considering the \{value the price that's related to the value of assorted system elements that need AN improvement within the base value of MTBF.

1.Based on the actual method system configuration draw the corresponding irresponsibleness diagram (RBD).

2.Fix the time amount or note down the time interval throughout that the failure knowledge for a specific part is accessible. This time amount ought to be ideally as long as attainable.

3. Obtain the time to failure of every part throughout the fastened period of time and additionally count the amount of failures throughout the interval.

4.Calculate MTBF by taking the average of time to failure for every of the elements.

\section{CONCLUSIONS}




\section{The American Journal of \\ Engineering and Technology}

VOLUME01 ISSUE01

The management tabulation technique was used to monitor the failure of parts and thereby make the benchmark worth. Method responsibility study was conducted at completely different industrial things mistreatment the developed model. The key inquiry findings area unit listed below.

1) Management tabulation technique will be applied to any method business to get the benchmark values. 2)The economic practicability of elevating the existing parts to the benchmark standards is evaluated by considering the investment required on International Journal of Mechanical Engineering and Technology.

3) The internet result of elevating the existing parts to the benchmark standards needn't essentially be positive. It depends upon factors like amendment in accessibility, years of operation once modification and conjointly time worth of cash. The savings that will be generated over amount of time will be quantified by considering factors like initial investment, operation and maintenance and interest and is pictured by NE.

4) In case of systems that area unit changed for reasons like improvement in energy potency, the model will be used as a technique of comparison of alternatives. The methodology involves comparison the assembly and maintenance figures by incorporating accessibility before and once modification. The accessibility figures admire the benchmark values area unit thought-about in every case.

\section{REFERENCES}

1. Apostolicism G (2004). However helpful is quantitative risk assessment? Risk Anal.

2. Bain $\sqcup$. Inquiry of linear failure rate life testing distributions.

3 Cordier, C., M. Fayot, A. Leroy and A. Petit. (1997) Integration of method simulations in convenience studies. Irresponsibleness Engineering \& System Safety.

4 Davidson, J. (1998) the irresponsibleness of mechanical systems. Technology Publications restricted.

5 Dillon, B. S. Life distributions. IEEE Transactions on irresponsibleness. 